\title{
Resolving potential conflicts between different heathland ecosystem services through adaptive management
}

\author{
"Isabel Alonso, "*Werner Härdtle \\ *Natural England, Temple Quay House, 2 The Square, Temple Quay, Bristol BS1 6DG, UK \\ e-mail: isabel.alonso@naturalengland.org.uk \\ **University of Lueneburg, Institute of Ecology, Scharnhorststr. 1, 21335 Lueneburg, Germany, \\ e-mail: haerdtle@uni-lueneburg.de
}

\begin{abstract}
Climate change and consistently high nitrogen atmospheric deposition are causing changes in the ecology and physiognomy of heathland habitats which affect the ecosystem services that they provide. In this presentation we quantified how traditional management practices affect these services, but also how they could be adapted to the current conditions in order to maintain the features that visitors and wildlife value on heathlands.
\end{abstract}

Key words: biodiversity, environmental changes; carbon storage; nitrogen leaching

\section{Introduction}

Heathland ecosystems are amongst the oldest cultural landscapes in Europe, host a huge proportion of the biodiversity typical of open acidic sites, and are landscapes of high conservation value (e.g. as recognised by international frameworks such as the EC Habitat Directive 2010). Besides this exceptional value that heathlands have from a nature conservation point of view, they provide important ecosystems services (ESs), for example in terms of carbon and nitrogen storage, groundwater recharge, or their appreciation as landscapes of high recreational value (van der Wal et al, 2014).

Since heathlands occur in a narrow set of environmental conditions such as low-nitrogen environments and are predominantly found in (sub-)Atlantic climate (Gimingham, 1972), they are considered highly vulnerable to both climate and atmospheric changes (Fagúndez, 2013). It is conceivable, for example, that increasing frequency and severity of summer droughts might affect the vitality or rejuvenation of characteristic dwarf shrubs such as $\mathrm{Cal}$ - luna vulgaris (Wessel et al, 2004). Atmospheric nitrogen deposition has been shown to adversely affect biodiversity patterns of heathlands, often due to an encroachment of grasses such as Deschampsia flexuosa or Molinia caerulea (Calvo et al., 2007). On the other hand, more intensive adaptive management, eg higher grazing pressure, more frequent burning or bare ground creation to maintain the diverse vegetation structure, may result in larger carbon emissions (Alonso et al, 2010).

Two questions therefore arise: 1) To what extent will climate and atmospheric changes affect such ecosystem functions in heathlands?, and 2) Do adaptive management measures have the potential to mitigate or even resolve potential conflicts arising from the protection of ESs provided by heaths?

The main objectives of this paper are to quantify how different management measures affect these ESs and demonstrate that adaptive management measures, eg new mowing or grazing strategies (low-intensity/high-intensity mowing or grazing) could deliver both, the preservation of heathlands and the wide range of ESs they provide. The 
cost impact of these new approaches and possible tradeoffs between ESs that are associated with 'traditional' and 'adapted' management measures will also be considered.

\section{Methods}

We quantified the effects of typical heathland management measures on ESs such as carbon storage and nitrogen leaching, taking sites in the Lüeneburg Heath nature reserve (NW Germany) as an example. To this end we reassessed data on ecosystem responses to different management measures based on original analyses provided by Härdtle et al. (2007, 2009). For comparisons of ESs, all response variables (representing different ESs) were normalised to achieve values ranging between 0 and 1 . To visualise trade-offs between different ESs resulting from management measures we followed the approach of Foley et al. (2005).
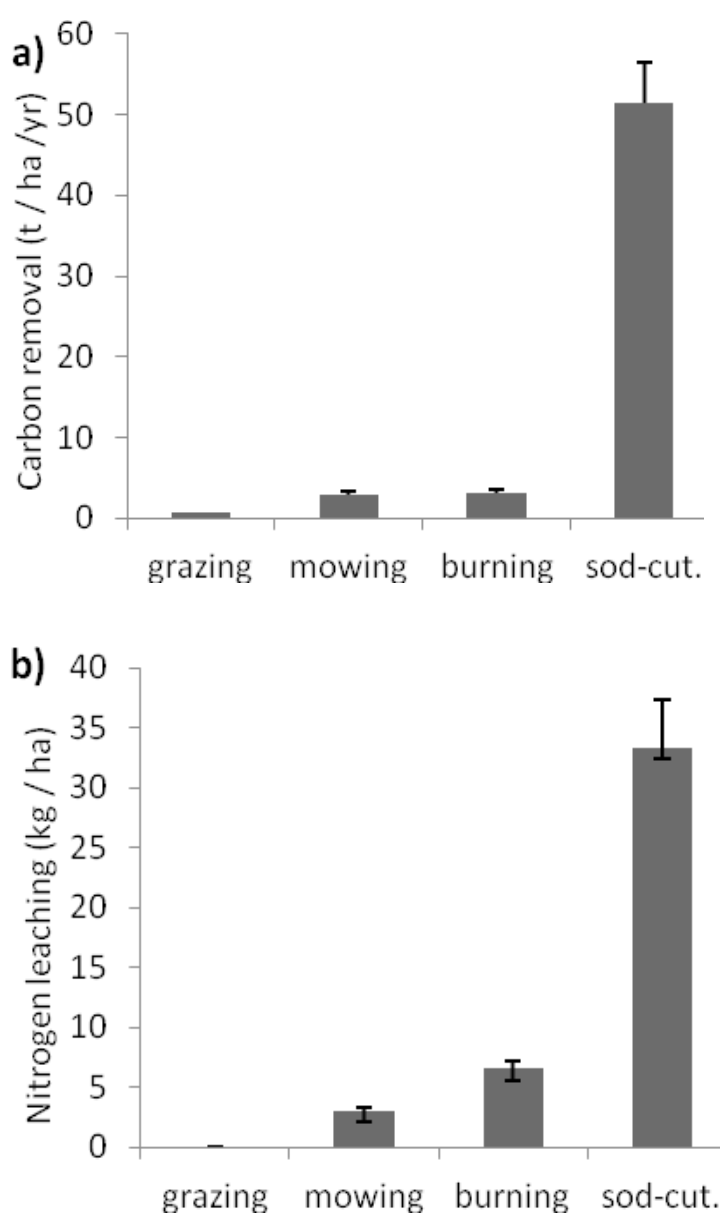

Figure 1. Impacts of four different management measures on heathland ecosystem services such as carbon storage (a) or nitrogen leaching (b)

\section{Results and discussion}

There is abundant published evidence on the, mostly negative, impacts of climate change and nitrogen deposition on heathland functioning (question 1). Traditional management measures could negatively affect important ESs such as carbon storage and nitrogen leaching (Fig. 1). However, there is less so on the adjustments that site managers are carrying out to ensure that valuable heathland attributes, such as presence of bare ground or a diverse vegetation structure are maintained (question 2).

Conceivably adaptive management strategies could be high-intensity mowing or less intensive grazing. Both measures would support the rejuvenation of important dwarf shrubs such as Calluna vulgaris, but would minimise negative impacts on carbon stores or nitrogen leaching. However, comparisons of trade-offs between ESs showed that there is no single management measure that sufficiently supports all the ESs compared. The interaction and tradeoffs between different ESs is a new and complex research area and, given the international importance of heathlands, we need to help land managers in their decisions to adopt the most efficient and less damaging options. However, there are time and resources implications for them as, for example a site which was only mowed every 10 years before may now need daily livestock checks and regular spot treatment of invasive species. This could be very difficult to achieve in many sites under the current economic constraints. However, if land mangers are aware of the impact of their management choices on the different ESs provided by the heathlands, they can tailor them to each site and balance them in such a way that minimises the negative impacts as much as possible within their means.

\section{References}

Alonso I., Weston K., Gregg R. \& Morecroft M., 2012, Carbon storage by habitat - Review of the evidence of the impacts of management decisions and condition on carbon stores and sources, Natural England Research Reports, Number NERR043.

Calvo L., Alonso I., Marcos E. \& de Luis E., 2007, Effects of cutting and nitrogen deposition on biodiversity in Cantabrian heathlands, Applied Vegetation Science, 10: 43-52.

Fagúndez J., 2013, Heathlands confronting global change: drivers of biodiversity loss from past to future scenarios, Annals of Botany, 111: 151-172.

Foley J.A. et al., 2005, Global consequnces of land use, Science, 309: 570-574.

Gimingham C.H., 1972, Ecology of Heathlands, Chapman and Hall, London. 
Härdtle W., von Oheimb G., Niemeyer M., Niemeyer T, Assmann T. \& Meyer, H., 2007, Nutrient leaching in dry heathland ecosystems: effects of atmospheric deposition and management, Biogeochemistry, 86: 201-215.

Härdtle W., von Oheimb G., Gerke A.K., Niemeyer M., Niemeyer T., Assmann T., Drees C., Matern A. \& Meyer H., 2009, Shifts in N and P budgets of heathland ecosystems: Effects of management and atmospheric inputs, Ecosystems, 12: 298-310. van der Wal R., Bonn A., Monteith D., Reed M., Blackstock K., Hanley N., Thompson D., Evans M. \& Alonso I., 2011, Chapter 5: Mountains, Moorlands and Heaths, [in:] UK National Ecosystem Assessment: Technical Report Broad Habitats, UNEP-WCMC, Cambridge.

Wessel W.W., Tietema A., Beier C., Emmett B.A., Peñuelas J. \& Riis-Nielsen T., 2004, A Qualitative Ecosystem Assessment for Different Shrublands in Western Europe under Impact of Climate Change, Ecosystems, 7, 662-671. 